\title{
A Modified Ridge Splitting Technique Using Autogenous Bone Blocks-A Case Series
}

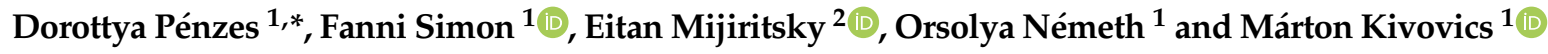 \\ 1 Department of Community Dentistry, Semmelweis University, 1088 Budapest, Hungary; \\ simon.fanni@dent.semmelweis-univ.hu (F.S.); nemeth.orsolya@dent.semmelweis-univ.hu (O.N.); \\ kivovics.marton@dent.semmelweis-univ.hu (M.K.) \\ 2 Head and Neck Maxillofacial Surgery, Department of Otolaryngology, Tel-Aviv Sourasky Medical Center, \\ Sackler Faculty of Medicine, Tel-Aviv University, Tel Aviv 62431, Israel; mijiritsky@bezeqint.net \\ * Correspondence: penzes.dorottya@dent.semmelweis-univ.hu
}

Received: 3 August 2020; Accepted: 7 September 2020; Published: 11 September 2020

check for updates

\begin{abstract}
Background: Alveolar atrophy following tooth loss is a common limitation of rehabilitation with dental implant born prostheses. Ridge splitting is a well-documented surgical method to restore the width of the alveolar ridge prior to implant placement. The aim of this case series is to present a novel approach to ridge expansion using only autogenous bone blocks. Methods: Patients with Kennedy Class I. and II. mandibles with insufficient bone width were included in this study. Ridge splitting was carried out with the use of a piezoelectric surgery device by preparing osteotomies and after mobilization of the buccal cortical by placing an autologous bone block harvested from the retromolar region as a spacer between the buccal and lingual cortical plates. Block-grafts were stabilized by osteosynthesis screws. Implant placement was carried out after a 3-month healing period. A total of 13 implants were placed in seven augmented sites of six patients. Results: Upon re-entry, all sites healed uneventfully. Mean ridge width gain was $2.86 \mathrm{~mm}$, range: $2.0-5.0 \mathrm{~mm}$. Conclusions: Clinical results of our study show that the modified ridge splitting technique is a safe and predictable method to restore width of the alveolar ridge prior to implant placement.
\end{abstract}

Keywords: mandibular ridge augmentation; piezo surgery; bone transplantation; alveolar bone loss; dental implantation

\section{Introduction}

Alveolar atrophy following tooth loss is a common limitation of rehabilitation with dental implant born prostheses. Following tooth extraction, the jaw undergoes alveolar atrophy. The amount of bone reduction is more significant in the mandible compared to the maxilla [1]. There are notable differences observed in the rate and degree of atrophy between the anterior and posterior segments of the mandible, with the posterior segments showing a higher degree of bone loss [2]. Furthermore, the direction of the absorption also shows significant differences. Initially after tooth extraction, the mandibular bone loss is mainly horizontal, while vertical resorption is more significant at a later stage [3]. Inadequate bone width for dental implant placement in the premolar and molar regions of the mandible is common in a late implant placement protocol. For the long-term stability of the hard tissues, at least $1.5 \mathrm{~mm}$ of bone surrounding the implant on both oral and vestibular aspect is required [4].

There have been numerous techniques described for augmenting the mandible with deficient bone width. These techniques include onlay grafting using bone blocks, guided bone regeneration (GBR), shell technique, and the swinging interpositional grafts technique [5]. Each technique has its own disadvantages, with the most common complications being tissue dehiscence, membrane displacement or collapse, bone resorption, donor site morbidity in case of autografts used, long healing 
time, and inadequate quality of the augmented bone. Furthermore, all grafting methods significantly increase the morbidity of the patients, treatment cost, and time [6].

Numerous biomaterials, such as autologous bone, allografts, xenografts, alloplastic materials (i.e., nanomaterials), biologic mediators, and stem cells, have been successfully applied in various techniques to restore the horizontal and vertical dimensions of the alveolar ridges prior to or at the time of dental implant placement $[7,8]$.

Tatum described the alveolar ridge splitting as a new way of alveolar ridge expansion [9]. The technique was later modified by Simion et al. [10] and Scipioni et al. [11].

Originally, the splitting is performed with chisel and hammer, later with rotating or oscillating saws $[12,13]$.

The use of ultrasound for medical surgery facilitated a new method for ridge expansion. Piezoelectricity was discovered in 1880 by Jacques and Pierre Curie [14], and its use for surgery was explored in the 1940s [15]. It works with selective hard tissue cutting in a safe and precise way [16], while minimizing the risk of nerve or membrane injury because the soft tissues can oscillate at the same amplitude as the tip of the instruments [17]. It provides cleaner operation areas, and better visibility in the surgical field than rotary instruments [18]. Furthermore, the ultrasonic device enables the surgeon to carry out curved osteotomies [18]. However, poor efficacy and slow cutting rates of the piezosurgical instruments may be disadvantages of such a surgical method [19].

The aim of this case series is to present a novel approach to ridge expansion using only autogenous bone blocks.

\section{Materials and Methods}

\subsection{Patient Population}

Patients who were periodontally healthy more than 18 years of age, with Kennedy Class I. and II. mandibles with insufficient bone width for implant placement, were included in our study.

Exclusion criteria were as follows:

- History of uncontrolled medical disorders;

- History of systemic diseases or medication that alter bone metabolism;

- $\quad$ Poor oral hygiene;

- Smoking.

Criteria for patient selection were as follows:

- Mandibular ridge width at least $3 \mathrm{~mm}$;

- Ridge height at least $11 \mathrm{~mm}$;

- Spongiosa between the two cortical plates at least $1 \mathrm{~mm}$ [20].

The procedures involved in the study were thoroughly explained to the patients, and each patient gave informed consent in writing.

The study was approved by the Regional and Institutional Committee of Science and Research Ethics (52158-2/2015/EKU [0425/15]) and The Office of the Chief Medical Officer of The National Public Health and Medical Officer Service (IF-14561-10/2015). All investigations reported have been carried out in accordance with the Helsinki Declaration.

Seven ridge splitting procedures were performed in the mandible of six patients (one male). After the 3-month healing period, 13 implants were placed.

\subsection{Surgical Procedure}

Patients were required to rinse with a $0.2 \%$ chlorhexidine solution for $1 \mathrm{~min}$ before surgery. Under local anesthesia, a full-thickness flap was raised from a crestal incision with a mesial releasing incision to access the alveolar ridge and the retromolar area. A midcrestal osteotomy was preformed, 
leaving a safety zone of at least $2 \mathrm{~mm}$ from the adjacent tooth [13]. Two vertical releasing osteotomies were performed at the mesial and distal ends of the mid-crestal osteotomy. Apically, the vertical osteotomies were connected horizontally with a superficial corticotomy. Osteotomies and corticotomies were carried out using a piezoelectronic device (NSK Variosurg3 Ultrasonic Bone Surgery System, NSK Europe GmbH, Eschborn, Germany.) Chisels were inserted in the midcrestal osteotomy to create a green-stick fracture to allow extensive mobilization of the buccal cortical.

After mobilization of the buccal cortical, an autologous bone block with dimensions corresponding to that of the bone defect created in the recipient site was harvested from the retromolar area and was placed as a spacer between the buccal and lingual cortical plates. The block was stabilized using osteosynthesis screws (Meisinger Screw System, Hager and Meisinger GmbH, Neuss, Germany). The surgical steps are demonstrated in Figure 1. Both lingual and buccal flaps were mobilized to allow tension-free primary closure. The flap was closed with horizontal mattress sutures, and then single interrupted sutures closed the edges of the flaps. Suture removal took place after 14 days. All patients received amoxicillin and clavulanate (Aktil Duo $875 \mathrm{mg} / 125 \mathrm{mg}$, Sandoz Hungária Kft., Budapest, Hungary) $1 \mathrm{~g}$ twice per day, starting at the day of the surgery and continuing for 7 days. In case of amoxicillin allergy, clindamycin (Dalacin 300 mg, Pfizer Inc., New York, NY, USA) was prescribed four times a day for 7 days. Furthermore, a non-steroid anti-inflammatory drug, diclofenac (Cataflam $50 \mathrm{mg}$, Novartis Hungária Kft., Budapest, Hungary), 3 times a day for 3 days, and $0.2 \%$ chlorhexidine mouth rinse (Corsodyl, GlaxoSmithKline Consumer Healthcare GmbH \& Co. KG, München, Germany), twice a day for 2 weeks, were prescribed to the patients. During the healing period, patients did not wear temporary prostheses.

Surgical re-entry took place after 3 months of healing. Implant bed preparation was carried out with rotatory instruments powered by a surgical micromotor (MasterSurg Surgical Systems, KaVo Dental Systems Japan, Co., Ltd., Tokyo, Japan). A trephine drill with an external diameter of $3.0 \mathrm{~mm}$ and an internal diameter of $2.0 \mathrm{~mm}$ (330 205486001020 Hager and Meisinger GmbH, Neuss, Germany) with external cooling at a drill rotation speed of $800 \mathrm{rpm}$ to the depth of $8 \mathrm{~mm}$ was used to remove bone core biopsy samples for histologic analysis. Implant beds were finalized according to the instructions of the implant manufacturer at a rotation speed of $800 \mathrm{rpm}$. Implants (Nobel Replace Conical Connection, Nobel Biocare AG, Kloten, Switzerland) were placed submerged in the augmented bone. Implant uncovery procedure took place 3 months after implant placement.

Patients were treated in outpatient care settings for minor surgeries without specific thromboprophylaxis prescribed. Patients were recalled the day following surgery to control postoperative bleeding. All surgical interventions were carried out by the same operator (DP).
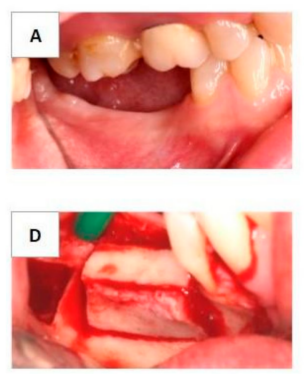
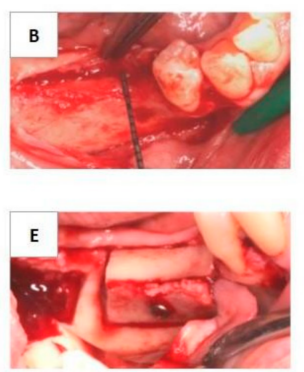
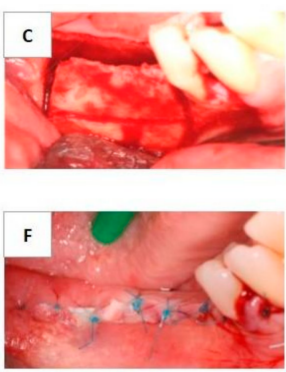

Figure 1. Clinical illustration of the surgical procedure of the modified ridge splitting. (A) Preoperative view of the atrophied alveolar ridge. (B) Full thickness flap preparation. (C) Buccal view of the osteotomies and the corticotomy. (D) The autologous bone block graft placed in the recipient site.

(E) The graft was stabilized with osteosynthesis screws. (F) Tension free primary closure.

\subsection{Clinical Measurement}

Clinical measurements were carried out using Williams probe (Karl Hammacher GmbH, Solingen, Germany) prior to ridge splitting surgery after the full thickness flap elevation, to evaluate the width 
of the alveolar ridge (preoperative measurement) and after a 3-month healing period, before implant placement (postoperative measurement). The width of the alveolar ridges was measured at 3, 10, and $15 \mathrm{~mm}$ from the reference point, which was the distal marginal bone of the last tooth of the quadrant. To ensure that preoperative and postoperative measurement sites corresponded, we placed the tip of the Williams probe on the reference point described and the markings of the probe to the highest ridge of the lingual cortical.

\section{Results}

A total of six patients participated in the present study; median age was 56.5 years (range: $42-77$ years). Seven staged ridge split procedures for lateral augmentation in the posterior mandible were performed. All sites showed improvement in the ridge width. There were notable differences in the ridge width gain at 3, 10, and $15 \mathrm{~mm}$. Excellent ridge width gain was observed at $10 \mathrm{~mm}$, mean ridge width gain was $2.86 \mathrm{~mm}$ range: $2.0-5.0 \mathrm{~mm}$. At $3 \mathrm{mms}$ and $15 \mathrm{mms}$, moderate width gain was achieved. Pre- and postoperative measurements are presented in Table 1.

All sites healed uneventfully, and upon re-entry excellent bone regeneration was observed with perfect ossification of the osteotomies, except for one site, which needed secondary augmentation. Clinically at the second surgery, the augmented area showed dense cortical bone at the coronal part of the ridge.

All augmented areas were sufficiently wide to accommodate implants according to the prosthetic plan. None of the implants failed at the 6-month control. The fixed dental prostheses were successful and functional in all cases.

The intra- and postoperative pain and swelling were comparable to other dentoalveolar surgeries. There were no cases of infection and no complications at the donor site. In one of the cases, the buccal cortical plate fractured during the ridge splitting procedure. The fractured plate was stabilized by osteosynthesis screws to the lingual cortex, and the healing was uneventful. In one of the cases upon reentry, connective tissue was observed between the buccal and lingual corticals. However, the block graft has carried out its space maintaining purpose. After careful debridement of the soft tissue, the implant bed was prepared. The implant placed in this site achieved primary stability and was anchored in the apical part of the ridge. The intrabony crater-like defect was regenerated with the guided bone regeneration technique (GBR) using bovine bone mineral matrix graft (creos xenogain, Nobel Biocare AG, Kloten, Switzerland) and nonresorbeable membrane (Permamem, Botiss biomaterials $\mathrm{GmbH}$, Zossen, Germany.)

None of the patients in our study had a history of congenital bleeding disorders. None of the patients received anticoagulants; one of the patients was on antiplatelet medication. At the control appointments, no postoperative hemorrhage was observed. 
Table 1. Pre- and postoperative measurements of the alveolar ridges, and the characteristics of the inserted implants (A—Need for secondary augmentation, B-Buccal cortical plate fractured during the ridge splitting procedure) (MR—right side of the mandible, ML—left side of the mandible).

\begin{tabular}{|c|c|c|c|c|c|c|c|c|c|c|c|c|c|c|}
\hline \multirow[b]{2}{*}{ Patients } & \multirow[b]{2}{*}{ AGE } & \multirow{2}{*}{$\begin{array}{c}\text { SEX } \\
\text { (M = Male, } \\
\text { F = Female })\end{array}$} & \multirow{2}{*}{$\begin{array}{c}\text { Surgical } \\
\text { Area }\end{array}$} & \multicolumn{3}{|c|}{$\begin{array}{l}\text { Preoperative } \\
\text { Measurement }\end{array}$} & \multicolumn{3}{|c|}{$\begin{array}{l}\text { Postoperative } \\
\text { Measurement }\end{array}$} & \multicolumn{3}{|c|}{ Ridge Width Gain } & \multirow{2}{*}{$\begin{array}{l}\text { Position of } \\
\text { the Implants }\end{array}$} & \multirow{2}{*}{$\begin{array}{l}\text { Diameter and } \\
\text { Length of the } \\
\text { Implants (mm) }\end{array}$} \\
\hline & & & & $\begin{array}{c}3 \\
\mathrm{~mm}\end{array}$ & $\begin{array}{c}10 \\
\mathrm{~mm}\end{array}$ & $\begin{array}{c}15 \\
\mathrm{~mm}\end{array}$ & $\begin{array}{c}3 \\
\mathbf{m m}\end{array}$ & $\begin{array}{c}10 \\
\mathrm{~mm}\end{array}$ & $\begin{array}{c}15 \\
\mathrm{~mm}\end{array}$ & $\begin{array}{c}3 \\
\mathrm{~mm}\end{array}$ & $\begin{array}{c}10 \\
\mathrm{~mm}\end{array}$ & $\begin{array}{c}15 \\
\mathrm{~mm}\end{array}$ & & \\
\hline \multirow{2}{*}{ Patient 1} & \multirow{2}{*}{56} & \multirow{2}{*}{ M } & ML & 5.0 & 4.0 & 5.0 & 5.0 & 8.0 & 6.0 & 0.0 & 4.0 & 1.0 & $\begin{array}{l}36 \\
37\end{array}$ & $\begin{array}{l}3.5 \times 10 \\
4.3 \times 10\end{array}$ \\
\hline & & & MR & 5.0 & 3.0 & 4.0 & 6.0 & 5.0 & 5.0 & 1.0 & 2.0 & 1.0 & $\begin{array}{l}44 \\
46\end{array}$ & $\begin{array}{c}3.5 \times 10 \\
3.5 \times 8\end{array}$ \\
\hline Patient 2 A & 77 & $\mathrm{~F}$ & MR & 7.0 & 4.0 & 5.0 & 9.0 & 9.0 & 9.0 & 2.0 & 5.0 & 4.0 & $\begin{array}{l}45 \\
46\end{array}$ & $\begin{array}{l}3.5 \times 10 \\
3.5 \times 10\end{array}$ \\
\hline Patient $3^{B}$ & 44 & $\mathrm{~F}$ & MR & 5.0 & 5.0 & 7.0 & 6.0 & 8.0 & 9.0 & 1.0 & 3.0 & 2.0 & $\begin{array}{l}45 \\
46\end{array}$ & $\begin{array}{l}3.5 \times 10 \\
4.3 \times 10\end{array}$ \\
\hline Patient 4 & 57 & $\mathrm{~F}$ & ML & 4.0 & 7.0 & 6.0 & 8.0 & 9.0 & 7.0 & 4.0 & 2.0 & 1.0 & 36 & $4.3 \times 8$ \\
\hline Patient 5 & 70 & $\mathrm{~F}$ & MR & 4.0 & 4.0 & 4.0 & 5.0 & 6.0 & 7.0 & 1.0 & 2.0 & 3.0 & $\begin{array}{l}45 \\
46\end{array}$ & $\begin{array}{l}3.5 \times 8 \\
3.5 \times 8\end{array}$ \\
\hline Patient 6 & 42 & $\mathrm{~F}$ & MR & 4.0 & 6.0 & 5.0 & 7.0 & 8.0 & 8.0 & 3.0 & 2.0 & 3.0 & $\begin{array}{l}44 \\
46\end{array}$ & $\begin{array}{l}4.3 \times 11.5 \\
4.3 \times 11.5\end{array}$ \\
\hline Mean & - & - & - & 4.86 & 4.71 & 5.14 & 6.57 & 7.57 & 7.29 & 1.71 & 2.86 & 2.14 & - & - \\
\hline
\end{tabular}




\section{Discussion}

For the long-term success of dental implants, augmentation of the narrow alveolar ridge is necessary prior to implant placement. There are various approaches for lateral augmentation, i.e., onlay grafting using bone blocks [21], membrane protected blocks [22], GBR [23-25], and interpositional grafts [26].

Simion et al. described the defect created during the ridge splitting procedure as a "self-space making" defect [10], a four-wall intrabony box. This box can contain the graft materials better, than a one-wall defect observed at onlay grafting, or the GBR technique. Cortellini et al. described that the shape of the created defect is favorable for the formation of new vital bone [27].

The success of ridge expansion is not only dependent on the shape of the defect, but also on the grafting material used. Probably the most controversy surrounding the ridge splitting technique is the type of grafting material applied. In the literature autografts, xenografts and alloplastic materials were applied successfully in ridge splitting $[6,12,13,26,28]$. Furthermore, ridge expansion could be carried out without the use of graft materials. According to Gonzalez-Gracia et al., using a mixture of autogenous bone graft and allogenic bovine particulated bone graft showed predictable results in terms of bone regeneration [29]. According to histological results after the 4-month healing period the bone core biopsy specimens showed de novo formation of mature bone, with residual particles of the bone graft material [29].

Furthermore, Ramal et al. compared conventional ridge split with xenograft particulate covered by a collagen membrane with a modified bone expansion, in which the graft material was autogenous bone particles harvested from the ipsilateral surgical site. After six months of healing, there was no statistical difference in the crestal bone width between the two groups [30].

Other authors chose to use no graft material in the bone defect created by expansion. In these studies, dental implants were inserted during the ridge splitting surgery, to provide the function of a spacer to avoid the collapse of the bone defect [31-33]. The expanded site may be left empty, because it can be considered as a self-containing defect with four cortical walls, and complete bony regeneration is possible [34]. Scipioni et al. examined the micromorphology of the augmented areas following a graftless ridge splitting procedure using histological methods. After the 16-month healing period a mature, regenerated bone was observed [35].

Dottore et al. conducted vertical augmentation in the posterior mandible with interpositional autogenous bone graft. With this technique, the cortical bone was displaced coronally, where stable bone formation was observed, which contributed to the long-term stability of the inserted implants [5].

In their study, Mahmoud et al. treated 562 patients with a flapless piezotome crest split procedure using a synthetic self-hardening biphasic bone graft material. The baseline and final width of the alveolar ridge were $1.9 \pm 0.4 \mathrm{~mm}$ and $6.5 \pm 0.7 \mathrm{~mm}$, respectively [36]. Flapless surgical methods allow for better blood supply and decreased marginal bone resorption, unlike full thickness flap preparation; however, our modified surgical approach required the elevation of a mucoperiosteal flap to allow the immobilization of the block grafts with the use of osteosynthesis screws [37,38].

Nickeninig et al. presented a novel approach for ridge splitting assisted by navigated surgery following virtual planning. Successive surgical templates were used to transport the virtually determined splitting vector, to guide the piezosurgical osteotomy, expansion screws, and spreading chisels, and to place the implants. Particulated autologous bone was used as filler in the bone defect created during the intervention [39].

In their study, Albanese et al. carried out ridge splitting using a piezosurgical device with simultaneous implant placement. Fresh frozen tissue bank allograft was used as filler in the bone defect covered by a double layer of membranes. Compared to autologous bone, allografts eliminate donor site morbidity; allografts are available in sufficient quantity, however, and higher costs and lack of vital osteoblasts are considered as their disadvantages [40].

In the present study, an autologous bone block harvested from the retromolar area was used to provide the function of a spacer. Autologous bone is considered the gold standard of bone graft materials due to its osteogenic, osteoinductive, and osteoconductive properties [41]. Donor site 
morbidity is considered a disadvantage of the use of autologous bone. However, in the surgical method described in this case study, donor and recipient regions are in close proximity and accessed from the same flap, which may decrease the postoperative discomfort of the patient.

The healing period in ridge splitting described in the literature varies between 4 and 6 months [26,28], with most techniques involving implant placement simultaneously $[6,20,29,42]$. The modified approach described in the present study consists of grafting with autologous bone blocks and second stage implant placement after 3 months. Depending on the implant system and loading protocol used, this means an overall healing period of 3-6 months. Longer healing time may be a weakness of this surgical method.

According to the review of Williams et al., venous thromboembolism is among the most common complications in inpatient healthcare settings [43]. Our modified technique was carried out in ambulatory settings without thromboprophylaxis prescribed, because according to the Official Journal of International Union of Angiology [44] and American College of Chest Physicians Evidence-Based Clinical Practice Guideline [45], the use of specific thromboprophylaxis is not recommended for low-risk general surgery patients who are undergoing minor procedures and have no additional thromboembolic risk factors. However, the use of piezosurgical instruments instead of rotational instruments increases the time of the surgery, where this prolonged time can manifest in a higher risk of extensive bleeding, especially in patients with congenital or acquired bleeding disorders [46,47]. Therefore, patients were closely monitored for postoperative hemorrhage.

Surgical instrumentation of ridge splitting procedures have undergone development since the technique was first introduced. The earliest ridge split procedures were carried out with chisels and hammers [10,13]. In the 2000s, rotating [13] and oscillating instruments appeared [48] for ridge splitting.

The use of the chisel and mallet may cause significant discomfort to the patient. Rotating instruments lower the patient's stress level, but may lead to thinner, weakened cortical bone plates because of the relatively wide diameter of burs used.

Piezoelectric instruments provide a good alternative to the above-described methods because of the thin tips that enable the sparing management of bone. Further advantages of such a device include less patient discomfort, minimizing the risk of soft tissue or nerve injury, and facilitated surgical accuracy by allowing preparation of curved osteotomies. However, slow cutting rates and increased surgical time may be a disadvantage of piezoelectrical instruments $[16,17]$.

\section{Conclusions}

Within the limitations of the present study, we have concluded that the modified ridge splitting technique using autologous bone block grafts is an effective method to restore the width of the alveolar ridge prior to implant placement.

Author Contributions: Conceptualization, M.K., O.N.; methodology, M.K.; validation, E.M.; formal analysis, O.N.; investigation, D.P., F.S.; resources, O.N.; data curation, D.P., F.S.; writing-original draft preparation, D.P.; writing-review and editing, D.P., M.K.; visualization, D.P.; supervision, E.M.; project administration, E.M.; funding acquisition, F.S., O.N. All authors have read and agreed to the published version of the manuscript.

Funding: This research was funded by NSK Europe GmbH and Hungarian Dental Association.

Conflicts of Interest: This review article was supported by the NSK Europe GmbH and Hungarian Dental Association. These two institutes provided the piezoelectronic device (NSK Variosurg3 Ultrasonic Bone Surgery System) used in the study.

\section{References}

1. Tallgren, A. The continuing reduction of the residual alveolar ridges in complete denture wearers: A mixed-longitudinal study covering 25 years. J. Prosthet. Dent. 1972, 27, 120-132. [CrossRef]

2. Ulm, C.; Tepper, G.; Blahout, R.; Rausch-Fan, X.; Hienz, S.; Matejka, M. Characteristic features of trabecular bone in edentulous mandibles. Clin. Oral Implants Res. 2009, 20, 594-600. [CrossRef] [PubMed] 
3. Reich, K.M.; Huber, C.D.; Lippnig, W.R.; Ulm, C.; Watzek, G.; Tangl, S. Atrophy of the residual alveolar ridge following tooth loss in an historical population. Oral Dis. 2011, 17, 33-44. [CrossRef] [PubMed]

4. Yoda, N.; Zheng, K.; Chen, J.; Li, W.; Swain, M.; Sasaki, K.; Li, Q. Bone morphological effects on post-implantation remodeling of maxillary anterior buccal bone: A clinical and biomechanical study. J. Prosthodont. Res. 2017, 61, 393-402. [CrossRef]

5. Dottore, A.M.; Kawakami, P.Y.; Bechara, K.; Rodrigues, J.A.; Cassoni, A.; Figueiredo, L.C.; Piattelli, A.; Shibli, J.A. Stability of implants placed in augmented posterior mandible after alveolar osteotomy using resorbable nonceramic hydroxyapatite or intraoral autogenous bone: 12-month follow-up. Clin. Implant Dent. Relat. Res. 2014, 16, 330-336. [CrossRef]

6. Santagata, M.; Guariniello, L.; D'Andrea, A.; Tartaro, G. A modified crestal ridge expansion technique for immediate placement of implants: A report of three cases. J. Oral Implantol. 2008, 34, 319-324. [CrossRef]

7. Sheikh, Z.; Sima, C.; Glogauer, M. Bone replacement materials and techniques used for achieving vertical alveolar bone augmentation. Materials 2015, 8, 2953-2993. [CrossRef]

8. Zakrzewski, W.; Dobrzynski, M.; Rybak, Z.; Szymonowicz, M.; Wiglusz, R.J. Selected Nanomaterials' Application enhanced with the use of stem cells in acceleration of alveolar bone regeneration during augmentation process. Nanomaterials 2020, 10, 1216. [CrossRef]

9. Tatum, O. The omni implant system. Clarke's Clin. Dent. 1984, 5, 126-127.

10. Simion, M.; Baldoni, M.; Zaffe, D. Jawbone enlargement using immediate implant placement associated with a split-crest technique and guided tissue regeneration. Int. J. Periodontics Restor Dent. 1992, 12, 462-473.

11. Scipioni, A.; Bruschi, G.B.; Calesini, G. The edentulous ridge expansion technique: A five-year study. Int. J. Periodontics Restor Dent. 1994, 14, 451-459. [CrossRef]

12. Basa, S.; Varol, A.; Turker, N. Alternative bone expansion technique for immediate placement of implants in the edentulous posterior mandibular ridge: A clinical report. Int. J. Oral Maxillofac. Implant. 2004, 19, 554-558.

13. Coatoam, G.W.; Mariotti, A. The segmental ridge-split procedure. J. Periodontol. 2003, 74, 757-770. [CrossRef] [PubMed]

14. Curie, J.; Curie, P. Contractions et dilatations produites par des tensions dans les cristaux hémièdres à faces inclinées. C. R. Acad. Sci. Gen. 1880, 93, 1137-1140.

15. Lynn, J.G.; Zwemer, R.L.; Chick, A.J. The biological application of focused ultrasonic waves. Science 1942, 96, 119-120. [CrossRef] [PubMed]

16. Vercellotti, T.; De Paoli, S.; Nevins, M. The piezoelectric bony window osteotomy and sinus membrane elevation: Introduction of a new technique for simplification of the sinus augmentation procedure. Int. J. Periodontics Restor Dent. 2001, 21, 561-567.

17. Peñarrocha-Diago, M.; Peñarrocha-Diago, M.; Sanchez-Recio, C.; Peñarrocha-Oltra, D.; Romero-Millán, J. Osteotomy in direct sinus lift. A comparative study of the rotary technique and ultrasound. Med. Oral Patol. Oral Cir. Bucal 2012, 17, 457-461. [CrossRef]

18. Gonzalez-Garcia, A.; Diniz-Freitas, M.; Somoza-Martin, M.; Garcia-Garcia, A. Ultrasonic osteotomy in oral surgery and implantology. Oral Surg. Oral Med. Oral Pathol. Oral Radiol Endod. 2009, 108, 360-367. [CrossRef]

19. Leclercq, P.; Zenati, C.; Dohan, D.M. Ultrasonic bone cut part 2: State-of-the-art specific clinical applications. J. Oral Maxillofac. Surg. 2008, 66, 183-188. [CrossRef]

20. Ella, B.; Laurentjoye, M.; Sedarat, C.; Coutant, J.; Masson, E.; Rouas, A. Mandibular ridge expansion using a horizontal bone-splitting technique and synthetic bone substitute: An alternative to bone block grafting. Int. J. Oral Maxillofac. Implant. 2014, 29, 135-140. [CrossRef]

21. Aloy-Prosper, A.; Penarrocha-Oltra, D.; Penarrocha-Diago, M.; Penarrocha-Diago, M. The outcome of intraoral onlay block bone grafts on alveolar ridge augmentations: A systematic review. Med. Oral Patol. Oral Cir. Bucal 2015, 20, 251-258. [CrossRef] [PubMed]

22. Chappuis, V.; Cavusoglu, Y.; Buser, D.; von Arx, T. Lateral Ridge Augmentation Using Autogenous Block Grafts and Guided Bone Regeneration: A 10-Year Prospective Case Series Study. Clin. Implant. Dent. Relat. Res. 2017, 19, 85-96. [CrossRef] [PubMed]

23. Wang, R.E.; Lang, N.P. Ridge preservation after tooth extraction. Clin. Oral Implants Res. 2012, 23, 147-156. [CrossRef] [PubMed] 
24. Roccuzzo, M.; Ramieri, G.; Bunino, M.; Berrone, S. Autogenous bone graft alone or associated with titanium mesh for vertical alveolar ridge augmentation: A controlled clinical trial. Clin. Oral Implants Res. 2007, 18, 286-294. [CrossRef]

25. Antoun, H.; Sitbon, J.M.; Martinez, H.; Missika, P. A prospective randomized study comparing two techniques of bone augmentation: Onlay graft alone or associated with a membrane. Clin. Oral Implant. Res. 2001, 12, 632-639. [CrossRef]

26. Moro, A.; Gasparini, G.; Foresta, E.; Saponaro, G.; Falchi, M.; Cardarelli, L.; De Angelis, P.; Forcione, M.; Garagiola, U.; D'Amato, G.; et al. Alveolar ridge split technique using piezosurgery with specially designed tips. Biomed. Res. Int. 2017, 2017, 4530378. [CrossRef]

27. Cortellini, P.; Pini Prato, G.; Tonetti, M.S. Periodontal regeneration of human infrabony defects. II. Re-entry procedures and bone measures. J. Periodontol. 1993, 64, 261-268. [CrossRef]

28. Holtzclaw, D.J.; Toscano, N.J.; Rosen, P.S. Reconstruction of posterior mandibular alveolar ridge deficiencies with the piezoelectric hinge-assisted ridge split technique: A retrospective observational report. J. Periodontol. 2010, 81, 1580-1586. [CrossRef]

29. Gonzalez-Garcia, R.; Monje, F.; Moreno, C. Alveolar split osteotomy for the treatment of the severe narrow ridge maxillary atrophy: A modified technique. Int. J. Oral Maxillofac. Surg. 2011, 40, 57-64. [CrossRef]

30. Ali Ramal, M.E.M.; Mohammed, S.; Nahed, A. Modified staged ridge splitting technique versus conventional technique for horizontal expansion of narrow posterior mandible (randomized controlled clinical trial). Acta Sci. Dent. Sci. 2018, 2, 101-109.

31. Tang, Y.L.; Yuan, J.; Song, Y.L.; Ma, W.; Chao, X.; Li, D.H. Ridge expansion alone or in combination with guided bone regeneration to facilitate implant placement in narrow alveolar ridges: A retrospective study. Clin. Oral Implants Res. 2015, 26, 204-211. [CrossRef] [PubMed]

32. Langer, B.; Langer, L.; Sullivan, R.M. Planned labial plate advancement with simultaneous single implant placement for narrow anterior ridges followed by reentry confirmation. Int. J. Periodontics Restor. Dent. 2012, 32, 509-519.

33. Montero, J.; Lopez-Valverde, A.; de Diego, R.G. A retrospective study of the risk factors for ridge expansion with self-tapping osteotomes in dental implant surgery. Int. J.Oral Maxillofac. Implant. 2012, 27, 203-210.

34. Blus, C.; Szmukler-Moncler, S. Split-crest and immediate implant placement with ultra-sonic bone surgery: A 3-year life-table analysis with 230 treated sites. Clin. Oral Implants Res. 2006, 17, 700-707. [CrossRef]

35. Scipioni, A.; Bruschi, G.B.; Calesini, G.; Bruschi, E.; De Martino, C. Bone regeneration in the edentulous ridge expansion technique: Histologic and ultrastructural study of 20 clinical cases. Int. J. Periodontics Restor Dent. 1999, 19, 269-277.

36. Mahmoud, Z.T.; Wainwright, M.; Troedhan, A. Flapless piezotome crest split achieves comparable outcomes to autologous onlay grafts with significant less patient morbidity and complications-A randomized clinical study. J. Oral Maxillofac. Surg. 2020, S0278-2391, 30582-30586. [CrossRef]

37. Moghaddas, H.; Stahl, S.S. Alveolar bone remodeling following osseous surgery. A clinical study. J. Periodontol. 1980, 51, 376-381. [CrossRef]

38. Wood, D.L.; Hoag, P.M.; Donnenfeld, O.W.; Rosenfeld, L.D. Alveolar crest reduction following full and partial thickness flaps. J. Periodontol 1972, 43, 141-144. [CrossRef]

39. Nickenig, H.J.; Safi, A.F.; Matta, R.E.; Zöller, J.E.; Kreppel, M. 3D-based full-guided ridge expansion osteotomy-A case report about a new method with successive use of different surgical guides, transfer of splitting vector and simultaneous implant insertion. J. Craniomaxillofac Sug. 2019, 47, 1787-1792. [CrossRef]

40. Albanese, M.; Ricciardi, G.; Luciano, U.; Donadello, D.; Lucchese, A.; Gelpi, F.; Zangani, A.; De Santis, D.; Rizzini, A.; Rossetto, A.; et al. Alveolar splitting with Piezosurgeryß, bone bank grafts and NobelActive implants as an alternative to major bone grafting for maxillary reconstruction. Minerva Stomatol. 2019, 68, 3-10. [CrossRef]

41. Rocchietta, I.; Simion, M.; Hoffmann, M.; Trisciuoglio, D.; Benigni, M.; Dahlin, C. Vertical bone augmentation with an autogenous block or particles in combination with guided bone regeneration: A clinical and histological preliminary study in humans. Clin. Implant. Dent. Relat. Res. 2016, 18, 19-29. [CrossRef]

42. Demetriades, N.; Park, J.I.; Laskarides, C. Alternative bone expansion technique for implant placement in atrophic edentulous maxilla and mandible. J. Oral Implantol. 2011, 37, 463-471. [CrossRef] [PubMed]

43. Williams, B.; Indresano, A.T.; O'Ryan, F. Venous thromboembolism in oral and maxillofacial surgery: A review of the literature. J. Oral Maxillofac. Surg. 2011, 69, 840-844. [CrossRef] [PubMed] 
44. Nicolaides, A.; Hull, R.D.; Fareed, J. General, vascular, bariatric, and plastic surgical patients. Clin. Appl. Thromb. Hemost. 2013, 19, 122-133. [CrossRef]

45. Geerts, W.H.; Bergqvist, D.; Pineo, G.F.; Heit, J.A.; Samama, C.M.; Lassen, M.R.; Colwell, C.W. Prevention of venous thromboembolism: American college of chest physicians evidence-based clinical practice guidelines (8th Edition). Chest 2008, 133, 381s-453s. [CrossRef] [PubMed]

46. Simurda, T.; Dobrotova, M.; Skornova, I.; Sokol, J.; Kubisz, P.; Stasko, J. Successful use of a highly purified plasma von willebrand factor concentrate containing little FVIII for the long-term prophylaxis of severe (type 3) von willebrand's disease. Semin. Thromb. Hemost. 2017, 43, 639-641.

47. Simurda, T.; Kubisz, P.; Dobrotova, M.; Necas, L.; Stasko, J. Perioperative coagulation management in a patient with congenital afibrinogenemia during revision total hip arthroplasty. Semin. Thromb. Hemost. 2016, $42,689-692$.

48. Khoury, F.; Happe, A. Soft tissue management in oral implantology: A review of surgical techniques for shaping an esthetic and functional peri-implant soft tissue structure. Quintessence Int. 2000, 31, 483-499.

(C) 2020 by the authors. Licensee MDPI, Basel, Switzerland. This article is an open access article distributed under the terms and conditions of the Creative Commons Attribution (CC BY) license (http://creativecommons.org/licenses/by/4.0/). 